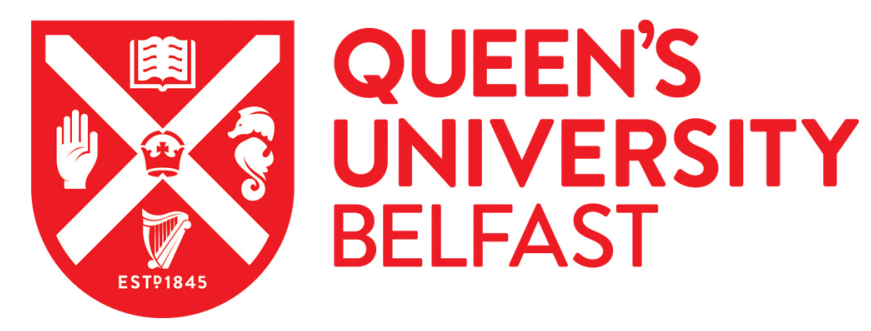

\title{
Multifunctional, low friction, antimicrobial approach for biomaterial surface enhancement
}

Irwin, N. J., Bryant, M. G., McCoy, C. P., Trotter, J. L., \& Turner, J. (2020). Multifunctional, low friction, antimicrobial approach for biomaterial surface enhancement. ACS Applied Bio Materials, 12. https://doi.org/10.1021/acsabm.9b01042

Published in:

ACS Applied Bio Materials

Document Version:

Peer reviewed version

Queen's University Belfast - Research Portal:

Link to publication record in Queen's University Belfast Research Portal

Publisher rights

(c) 2020 American Chemical Society. This work is made available online in accordance with the publisher's policies. Please refer to any applicable terms of use of the publisher.

\section{General rights}

Copyright for the publications made accessible via the Queen's University Belfast Research Portal is retained by the author(s) and / or other copyright owners and it is a condition of accessing these publications that users recognise and abide by the legal requirements associated with these rights.

Take down policy

The Research Portal is Queen's institutional repository that provides access to Queen's research output. Every effort has been made to ensure that content in the Research Portal does not infringe any person's rights, or applicable UK laws. If you discover content in the Research Portal that you believe breaches copyright or violates any law, please contact openaccess@qub.ac.uk. 


\title{
A Multifunctional, Low Friction, Antimicrobial Approach for Biomaterial Surface Enhancement
}

Nicola J. Irwin*a, Michael G. Bryant ${ }^{\mathrm{b}}$, Colin P. McCoy ${ }^{\mathrm{a}}$, Johann L. Trotter ${ }^{\mathrm{a}}$, Jonathan Turner $^{\mathrm{a}}$

aSchool of Pharmacy, Queen's University Belfast, 97 Lisburn Road, Belfast BT9 7BL, Northern Ireland, UK.

${ }^{\mathrm{b}}$ School of Mechanical Engineering, University of Leeds, Leeds

*To whom correspondence should be addressed. (Tel: +44 289097 2117; e-mail: n.irwin@qub.ac.uk)

\begin{abstract}
Poly(vinyl chloride) (PVC) biomaterials perform a host of life-saving and lifeenhancing roles when employed as medical devices within the body. High frictional forces between the device surface and interfacing tissue can, however, lead to a host of complications including tissue damage, inflammation, pain and infection. We herein describe a versatile surface modification method using multifunctional hydrogel formulations to increase lubricity and prevent common device-related complications. In a clinically-relevant model of the urinary tract, simulating the mechanical and biological environments encountered in vivo, coated candidate catheter surfaces demonstrated significantly lower frictional resistance than uncoated PVC, with reductions in coefficient of friction values of more than 300 -fold due to hydration of the surface-localised polymer network. Furthermore, this significant lubrication capacity was retained following hydration periods of up to 28 days in artificial urine at $\mathrm{pH} 6$ and $\mathrm{pH}$ 9, representing the $\mathrm{pH}$ of physiologically normal and infected urine respectively, and during 200 repeated cycles of applied frictional force. Importantly, the modified surfaces also displayed excellent antibacterial activity, which could be
\end{abstract}


facilely tuned to achieve reductions of $99.8 \%$ in adherence of common hospitalacquired pathogens, Staphylococcus aureus and Proteus mirabilis, relative to their uncoated counterparts through incorporation of chlorhexidine in the coating matrix as a model antiseptic. The remarkable, and $\mathrm{pH}$-independent, tribological performance of these lubricious, antibacterial and highly durable surfaces offers exciting promise for use of this PVC functionalization approach in facilitating smooth and atraumatic insertion and removal of a wide range of medical implants, ultimately maintaining user health and dignity.

\section{Keywords}

Functional surfaces; tribology; biomaterials; medical devices; infection

\section{Introduction}

Poly(vinyl chloride) (PVC) is one of the most widely employed biomaterials in medical implants and devices, including endotracheal tubes, urinary catheters and medical tubing. The diverse healthcare applications result from its relatively low cost, biological and chemical stability, and ready processability ${ }^{1}$. Insertion and removal of these devices can, however, adversely affect tissue integrity as a result of high frictional forces between the interfacing surfaces ${ }^{2}$. While the tribological behavior of artificial limbs, fraction fixation devices, and joint, cardiovascular and dental implants against human tissues has been extensively studied, the tribology of urinary catheter surfaces has, in contrast, received comparatively less attention to date, even though urinary catheters are the most frequently deployed medical device in clinical care ${ }^{3}$. 
Urinary catheters may be inserted intermittently to drain urine from the bladder when required, or remain in situ for up to three months between scheduled device changes when employed for the long-term management of incontinence ${ }^{4}$. Patients who undergo repeated catheterization with poorly lubricated indwelling and/or intermittent devices have, however, been reported to experience urethral bleeding, trauma, pain and inflammation as a result of high frictional forces between the biomaterial surface and interfacing tissues, which can ultimately result in infection and formation of urethral strictures ${ }^{5-8}$.

Increased lubricity of the device surface is anticipated to prevent associated pain and tissue trauma by decreasing frictional forces between the catheter surface and the urethral tissue upon device insertion and removal ${ }^{9}$. A common approach to promote smooth catheterization and reduce interfacial friction involves the application of lubricating agents or jelly-like materials, for example glycerin or lidocaine gels ${ }^{10}$. An alternative strategy to enhance usability of these devices and ensure sufficient robustness of the lubricious surface throughout the entire catheterization process involves the application of hydrophilic coatings $5,11,12$. These coatings have been widely applied to a range of implantable medical devices, such as endovascular catheters and guidewires, to minimize soft tissue damage upon interfacial contact with the vessel wall or urethra ${ }^{5,13}$. As a result of their lubricious properties they have also been applied in many industrial applications to reduce frictional forces and associated component wear ${ }^{13}$. Previous studies involving both in vitro and in vivo models for investigation of frictional properties of catheter surfaces have reported significantly lower interfacial frictional forces with the use of hydrated hydrophilic-coated catheters relative to their uncoated counterparts $11,12,14,15$. This effect is, however, commonly 
short-lived due to ready delamination of the coating as a result of high interfacial stresses between the device surface and the urethral tissue ${ }^{5}$.

In addition to the reported tissue damage, catheter surfaces also provide an attractive niche for colonization of infecting pathogens, of which the urease-producer Proteus mirabilis, which has been identified as one of the most common causes of catheterassociated urinary tract infections, is a notable example ${ }^{16,17}$. Infection with this pathogen results in elevation of urinary $\mathrm{pH}$ to levels up to $\mathrm{pH} 9.1$ as a result of ureasecatalysed hydrolysis of urea in the urine to ammonia, leading to precipitation of calcium and magnesium ammonium phosphates ${ }^{18,19}$. Accumulation of these crystals within the surface-attached bacterial biofilm leads to recurrent blockages of the catheter lumen in a reported $50 \%$ of all chronically catheterized patients, necessitating device replacement and, furthermore, increasing the risk of urinary retention and associated problems of pyelonephritis and septicemia ${ }^{20}$. The development of lubricious and durable surfaces which resist bacterial colonization and retain their friction-lowering properties within environments of varying $\mathrm{pH}$ is therefore urgently needed. Despite the wide variation in urinary $\mathrm{pH}$, resulting not only from infection but also from diet and drug therapy, the effect of $\mathrm{pH}$ on the tribological performance of coated catheter surfaces has, until now, never been examined ${ }^{21,22}$.

Herein, we describe the development of a robust and widely-applicable method to enhance functionality of PVC surfaces and resultant medical devices, including intermittent urinary catheters. The tribological and microbiological performance of the modified surfaces was evaluated under mechanically- and biologically-relevant conditions to inform the capacity of this approach for reducing frictional forces and 
ultimately preventing device-associated tissue trauma, infection and pain. PVC, representing the most widely employed biomaterial, was coated with a hydrogel formulation by a dip coating and UV curing process. Coefficients of friction (COF) of the modified surfaces were measured using a biologically-representative in vitro model of the tribological conditions experienced in the urinary tract in vivo after varying periods of incubation in deionized water $\left(\mathrm{dH}_{2} \mathrm{O}\right)$ and artificial urine of $\mathrm{pH} 6$ and $\mathrm{pH} 9$, representing normal and infected urinary $\mathrm{pH}$ respectively, against a polydimethylsiloxane (PDMS) probe. The tribological behaviour of the coated surfaces was, in addition, evaluated over 200 repeated frictional cycles to assess coating durability. Resistance to bacterial colonization was studied by challenging modified surfaces with the Gram-negative urinary pathogen P. mirabilis and the common Grampositive nosocomial pathogen Staphylococcus aureus.

\section{Materials and methods}

The coating components: ethylene glycol dimethacrylate (EGDMA), 2-hydroxy-4'-(2hydroxyethoxy)-2-methylpropiophenone, 2-hydroxyethyl methacrylate (2-HEMA), chlorhexidine and isopropanol; the artificial urine components: potassium dihydrogen orthophosphate, magnesium chloride hexahydrate, urea, calcium chloride dihydrate and chicken ovalbumin; and the neutralizer components: Tween 80 and azolectin, were obtained from Sigma-Aldrich (Dorset, UK). Kollidon 90F was supplied by BTC Europe (Germany). Poly(vinyl chloride) (PVC) sheets (unplasticised, $0.2 \mathrm{~mm}$ thickness) were purchased from Goodfellow Ltd. (Cambridge, UK). Phosphatebuffered saline (PBS), quarter-strength Ringer's solution (QSRS), tryptone soya broth (TSB), agar, glycerol and Mueller-Hinton broth (MHB) were obtained from Oxoid Ltd. 
(Hampshire, UK). Proteus mirabilis ATCC 35508 and Staphylococcus aureus ATCC 6538 (LGC Standards, Middlesex, UK) were maintained on cryopreservative beads (Protect Bacterial Preservation System, Technical Service Consultants Ltd., UK) in $10 \%$ glycerol at $-80^{\circ} \mathrm{C}$ and cultured by inoculation into $\mathrm{MHB}$ and incubation at $37^{\circ} \mathrm{C}$ when required for the in vitro microbiological assessments.

\subsection{Preparation of hydrogel-coated PVC}

The coating formulation with a final component composition of $37 \% \mathrm{w} / \mathrm{v}$ was prepared by dissolving the crosslinker EGDMA $\left(3.7 \mathrm{~g} \mathrm{~L}^{-1}\right)$, the hydrogel monomer 2-HEMA

(248 $\left.\mathrm{g} \mathrm{L}^{-1}\right)$, the thickening agent Kollidon 90F $\left(111 \mathrm{~g} \mathrm{~L}^{-1}\right)$ and the photoinitiator 2hydroxy-4'-(2-hydroxyethoxy)-2-methylpropiophenone (7.4 $\left.\mathrm{g} \mathrm{L}^{-1}\right)$ gradually, with stirring at ambient temperature, in a solvent mixture of isopropanol:water (2:1), under protection from light. In addition, chlorhexidine-loaded hydrogel (CLH) coatings were prepared for in vitro microbiological testing by the incorporation of chlorhexidine $(1 \mathrm{~g}$ $\mathrm{L}^{-1}$ ) to the previously described coating formulation. Substrates of PVC, as a model biomedical and catheter material, were etched in ethanol for $30 \mathrm{sec}$ and coated by a dip coating procedure using a withdrawal speed of $200 \mathrm{~mm} \mathrm{~min}^{-1}$. Samples were then dried at $60^{\circ} \mathrm{C}$ for $20 \mathrm{~min}$ and cured by irradiation with UVA light.

\subsection{Preparation of artificial urine}

Artificial urine (AU) was prepared using a composition based on that described by Cox et al. (1987), with the components listed in Table $1^{23}$. Two solutions (A and B) were prepared and mixed immediately before use in order to avoid precipitation of calcium phosphate in the form of brushite, which would lead to a corresponding reduction in the concentration of calcium and phosphate ions. 
Table 1: Composition of Artificial Urine

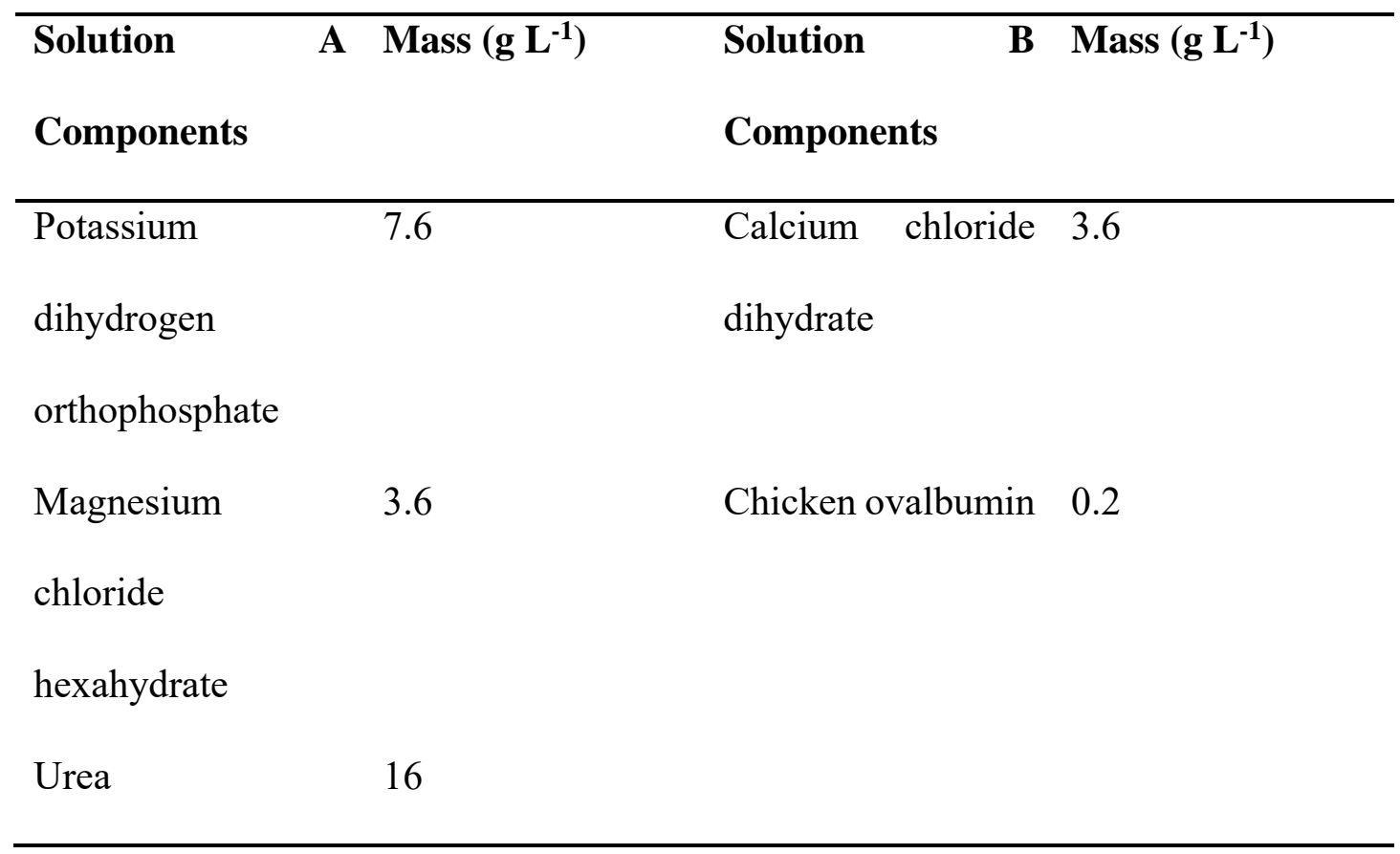

AU was adjusted to $\mathrm{pH}$ values of $\mathrm{pH} 6$ and 9 to simulate the $\mathrm{pH}$ of normal physiological and infected urine, respectively, by the addition of $1 \mathrm{M} \mathrm{HCl}$ or $\mathrm{NaOH}$, and sterilized by membrane filtration (pore size of $0.45 \mu \mathrm{m}$ ).

\subsection{Surface characterisation}

\subsubsection{Fourier transform infrared (FTIR) spectroscopy}

Functional groups of uncoated and coated sample surfaces were characterized by attenuated total reflectance (ATR) Fourier transform infrared (FTIR) spectroscopy using a Perkin-Elmer Spectrum Two spectrophotometer equipped with a diamond ATR accessory at a resolution of $4.0 \mathrm{~cm}^{-1}$. Spectra are an average of 128 scans recorded over the range $4000-650 \mathrm{~cm}^{-1}$. 


\subsubsection{Contact angle analysis}

Static contact angles of $\mathrm{dH}_{2} \mathrm{O}$ droplets $(4.0 \mu \mathrm{L})$ on the surface of coated and uncoated PVC substrates were measured using an Attension Theta optical tensiometer (Biolin Scientific, Sweden) mounted with a digital video camera and OneAttension software for image analysis. Samples were previously hydrated for $24 \mathrm{~h}$ in $\mathrm{dH}_{2} \mathrm{O}$ and values are reported as the mean \pm standard deviation of five measurements collected 1 to $1.5 \mathrm{sec}$ following droplet placement on ten replicate samples.

\subsubsection{Kinetics of coating hydration and dry-out}

The kinetics of coating hydration and dry-out at ambient temperature were determined by measuring coating thickness from cross-sectional images acquired using a Keyence VHX-2000E microscope every 10 min for $4 \mathrm{~h}$, with a final measurement at $24 \mathrm{~h}$, during hydration in, or following removal from, respectively, an aqueous solution of Toluidine blue $\mathrm{O}(\mathrm{TBO})$. Mean \pm standard deviation values were calculated from a minimum of five measurements at each time point.

\subsection{Tribological assessment}

Pin-on-plate reciprocating sliding friction tests on coated and uncoated PVC substrates were performed with an Anton-Paar Nano Tribometer in conjunction with InstrumX software. In this case, the counter surface pin was a PDMS hemisphere (Sylgard 184, DowCorning, USA) with a diameter $\varnothing$ of $6 \mathrm{~mm}$ and surface roughness $\mathrm{R}_{\mathrm{a}}<20 \mathrm{~nm}$. Figure 1 shows a schematic of the test arrangement used in this study. 


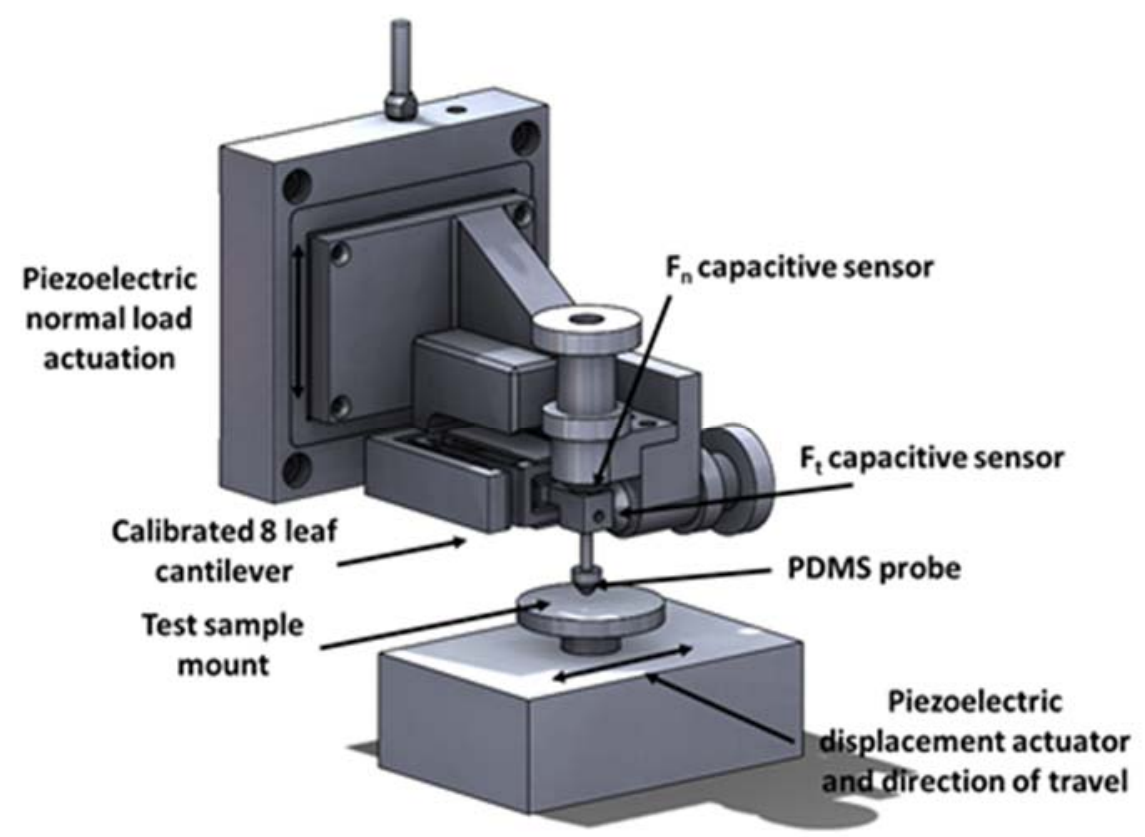

Figure 1. A schematic of the tribometer test arrangement.

The frictional properties of control and coated surfaces were quantified following incubation in $\mathrm{dH}_{2} \mathrm{O}$ and $\mathrm{AU}(\mathrm{pH} 6$ and $\mathrm{pH}$ 9) for $30 \mathrm{sec}, 24 \mathrm{~h}$, five days and 28 days. Immediately before tribological assessments, $100 \mu \mathrm{L}$ of the relevant media $\left(\mathrm{dH}_{2} \mathrm{O}\right.$ or AU) was dropped onto the surface as a lubricant. The PDMS counter probe was slowly lowered until a monotonic increase in force and then zeroed to mitigate any additional buoyancy forces. A normal load of $10 \mathrm{mN}$ was applied to the coated and uncoated PVC surfaces. Sliding was simulated via reciprocation of the PVC surfaces and the frictional forces quantified as a function of cycle position. The tests were conducted at a constant sliding speed of $2 \mathrm{~mm} / \mathrm{sec}$ at a sliding amplitude of $1 \mathrm{~mm}$ for 200 cycles, representing a total sliding distance of $400 \mathrm{~mm}$. This exceeds the distances expected during urinary catheterization, which are reported to be in the region of 40 and $200 \mathrm{~mm}$ for females and males respectively ${ }^{24}$. The instantaneous coefficient of friction (COF), $\mu$, was calculated by taking an average of frictional forces measured within the middle $20 \%$ of forward and reverse portions of the sliding cycle. The mean steady state COF was 
determined from data from the last fifty cycles when the transient behavior had stabilized. Each tribological test was performed with five replicate samples to obtain the mean \pm standard deviation values.

\subsection{Microbiological assessment}

\subsubsection{Preparation of challenge inocula}

Overnight broth cultures of respective bacteria, $P$. mirabilis and $S$. aureus, were centrifuged at $3000 \mathrm{~g}$ for $10 \mathrm{~min}$ and, after discarding the supernatant, the resulting bacterial pellet was re-suspended in PBS to an optical density equivalent to an inoculum concentration of $1 \times 10^{8} \mathrm{cfu} \mathrm{mL}^{-1}$, as verified by viable count.

\subsubsection{Neutralizer toxicity and efficacy tests}

A neutralizer composed of Tween $80\left(30 \mathrm{~g} \mathrm{~L}^{-1}\right)$, azolectin $\left(3 \mathrm{~g} \mathrm{~L}^{-1}\right)$ and deionized water was prepared for use in microbiological assessments of the CLH coatings to inhibit any residual antibacterial agent and ensure no inhibitory effects on microorganisms recovered from the sample surfaces, following the designated periods of bacterial challenge. Firstly, absence of toxicity of the neutralizer towards the bacterial cells was confirmed by adding $1 \mathrm{~mL}$ of the bacterial suspension $\left(1 \times 10^{8} \mathrm{cfu} \mathrm{mL}^{-1}\right)$ to the neutralizer solution $(9 \mathrm{~mL})$, vortexing and counting viable cell density after $10 \mathrm{~min}$ incubation. Controls were prepared using PBS in place of neutralizer. Viable counts of the bacterial suspensions were performed by serial dilution, with plating onto MHA and low-swarm agar for S. aureus and P. mirabilis, respectively. The neutralizer was considered non-toxic if colony counts for the test suspensions were $\leq 1 \log _{10}$ lower than the counts observed for the control suspensions. 
Secondly, efficacy of the neutralizer in quenching the activity of chlorhexidine was tested by adding $1 \mathrm{~mL}$ chlorhexidine solution $(1 \% \mathrm{w} / \mathrm{v})$ to the neutralizer solution $(8$ $\mathrm{mL})$. The solution was vortexed and after $10 \mathrm{~min}, 1 \mathrm{~mL}$ of the bacterial suspension (1 x $10^{8} \mathrm{cfu} \mathrm{mL}^{-1}$ ) was added, vortexed again and incubated for $10 \mathrm{~min}$. Controls were similarly prepared with the use of PBS instead of neutralizer. Viable counts of the test and control bacterial suspensions were performed and the neutralizer was considered effective if $\leq 1 \log _{10}$ reduction was observed in the neutralized bacterial suspension ${ }^{25}$.

\subsubsection{Bacterial adherence assessments}

Resistance of the hydrogel- and CLH-coated surfaces to bacterial colonization was assessed by challenging coated samples with $P$. mirabilis and $S$. aureus by incubation in infected AU. Suspensions of the respective bacteria with density of $1 \times 10^{8} \mathrm{cfu} \mathrm{mL}^{-}$

${ }^{1}$ were prepared in PBS as described above and a 1 in 100 dilution was carried out using AU supplemented with $0.5 \%$ TSB. Coated samples $(1 \mathrm{~cm} \times 1 \mathrm{~cm})$ and uncoated PVC, as controls, were placed into individual wells of a sterile 24 -well flat bottom tissue culture plate (Corning Inc., Corning, NY). Aliquots of bacterial suspension $(1 \mathrm{~mL})$ with a density of $1 \times 10^{6} \mathrm{cfu} \mathrm{mL}^{-1}$ were added to each well and the plates were shaken in an orbital incubator at $100 \mathrm{rpm}$ at $37^{\circ} \mathrm{C}$. After designated $4 \mathrm{~h}$ or $24 \mathrm{~h}$ incubation periods, samples were removed from the bacterial suspension and rinsed three times in QSRS to remove non-adherent bacteria. Adherent bacteria were then removed by sonicating samples for 10 min in neutralizer solution and vortexing for approximately $30 \mathrm{sec}$. The sonication technique has previously been demonstrated not to affect bacterial viability or morphology ${ }^{26}$. Viable counts of the resulting neutralizer solution were performed by the Miles and Misra serial dilution technique, with plating onto MHA and low-swarm agar for subsequent enumeration of adherent $S$. aureus and $P$. 
mirabilis, respectively, per sample ${ }^{27}$. Five replicates were assessed for each period of incubation and numbers of adherent bacteria on the coated samples have been expressed as percentage values relative to uncoated PVC controls ${ }^{28}$.

\subsection{Statistical analysis}

Statistical differences in COF values and sessile contact angles between coated surfaces and uncoated PVC controls were evaluated by an unpaired t test. Time-dependent measurements of coating thickness during hydration and dry-out were statistically analysed by a two-way analysis of variance. Resistance to bacterial colonization between hydrogel-coated, CLH-coated and uncoated PVC controls was evaluated by a one-way analysis of variance, whereas the effect of media $\mathrm{pH}$ and duration of hydration on COF values of the coated surfaces was statistically assessed by a two-way analysis of variance. Post-hoc comparisons between means of individual groups were performed using Tukey's honestly significant difference (HSD) test and in all cases differences were considered significant when $p<0.05$. All statistical calculations were performed with the use of GraphPad Prism 7 software.

\section{Results and discussion}

The findings from the experimental work are reported below and their relevance discussed to inform widespread use of this surface modification technique for engineering low friction, infection-resistant medical devices for optimal clinical use within environments of varying $\mathrm{pH}$. 


\subsection{Characterisation of coated surfaces}

\subsubsection{FTIR spectroscopy}

Overlaid ATR-FTIR spectra of uncoated PVC, hydrogel-coated PVC and CLH-coated PVC are presented in Figure 2.

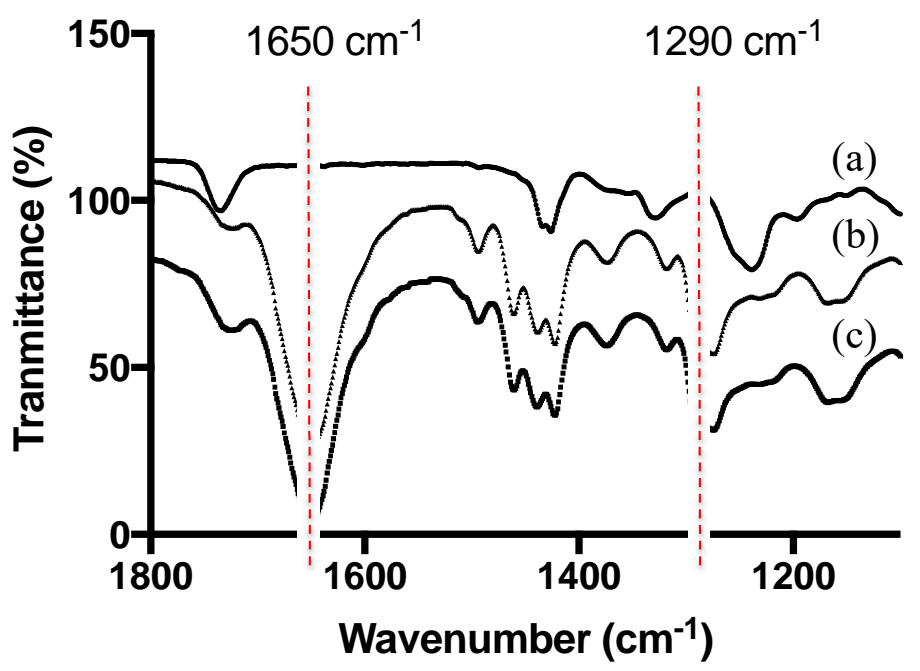

Figure 2. ATR-FTIR spectra of (a) uncoated PVC, (b) CLH-coated PVC and (c) hydrogel-coated PVC from $1800-1100 \mathrm{~cm}^{-1}$. Spectra have been offset vertically for clarity.

Spectral differences due to the presence of the coating include additional bands at 3400 $-3300 \mathrm{~cm}^{-1}, 1650 \mathrm{~cm}^{-1}$ and $1290 \mathrm{~cm}^{-1}$ attributed to stretching vibrations of $\mathrm{O}-\mathrm{H}, \mathrm{C}=\mathrm{O}$ and C-N moieties, respectively, within the HEMA and PVP components at the coated surface ${ }^{29}$. Additional bands within the spectra of the coated PVC at $2930 \mathrm{~cm}^{-1}$ and $1450-1420 \mathrm{~cm}^{-1}$ were ascribed to the alkyl backbones of HEMA and PVP moieties within the coating ${ }^{30}$. 


\subsubsection{Contact angle analysis}

To investigate the effect of these differences in chemical composition on wettability of the surface, the angles made by droplets of $\mathrm{dH}_{2} \mathrm{O}$ in contact with the solid surface were measured and representative images of these angles are displayed in Figure 3.

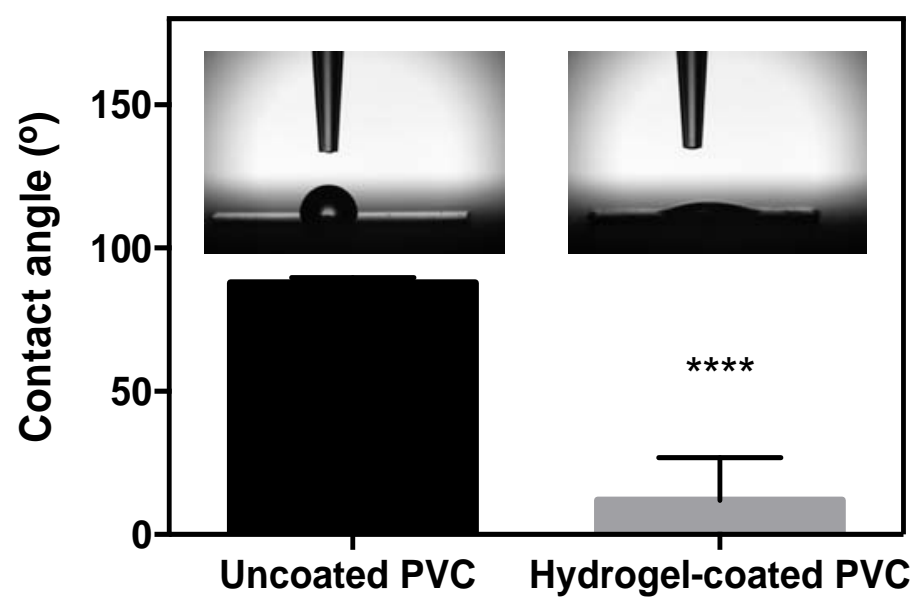

Figure 3. Contact angles of $\mathrm{dH}_{2} \mathrm{O}$ on surfaces of uncoated PVC and hydrogel-coated PVC. Values represent the mean \pm standard deviation of five measurements collected 1 to $1.5 \mathrm{sec}$ following droplet placement on ten replicate samples. $* * * *$ denotes significant difference in contact angle $(p<0.0001)$.

The significantly lower contact angles measured herein for the coated surfaces relative to their uncoated PVC counterparts $\left(11.9^{\circ} \pm 14.8^{\circ}\right.$ and $87.9^{\circ} \pm 1.8^{\circ}$ respectively $)$ reveal the enhanced hydrophilicity of the surface upon application of the hydrogel coating, with $\mathrm{dH}_{2} \mathrm{O}$ almost completely wetting the coated surface, as shown in Figure 3. This increased wettability was due to the presence of hydrophilic hydroxyl and carboxyl groups of the HEMA and PVP moieties within the coating ${ }^{13,31}$.

Surface wettability has previously been reported to play an important role in resulting lubricity and friction ${ }^{13,32}$. In addition, a higher degree of protein adsorption and 
bacterial adhesion has been observed on surfaces with moderate hydrophobicity $\left(\sim 90^{\circ} \mathrm{C}\right)$ relative to their more hydrophilic counterparts due to the promotion of adherence by hydrophobic interactions between the substrate and bacterial membrane 33,34 .

\subsubsection{Kinetics of coating hydration and dry-out}

Thickness of the coatings was measured at regular intervals during hydration in, and following removal from, an aqueous solution of TBO using optical microscopy. Representative cross-sectional images of hydrogel-coated PVC stained with TBO, and hydration and dehydration profiles of the hydrogel coating at ambient temperature are shown in Figures 4 (a) and (b) respectively. 

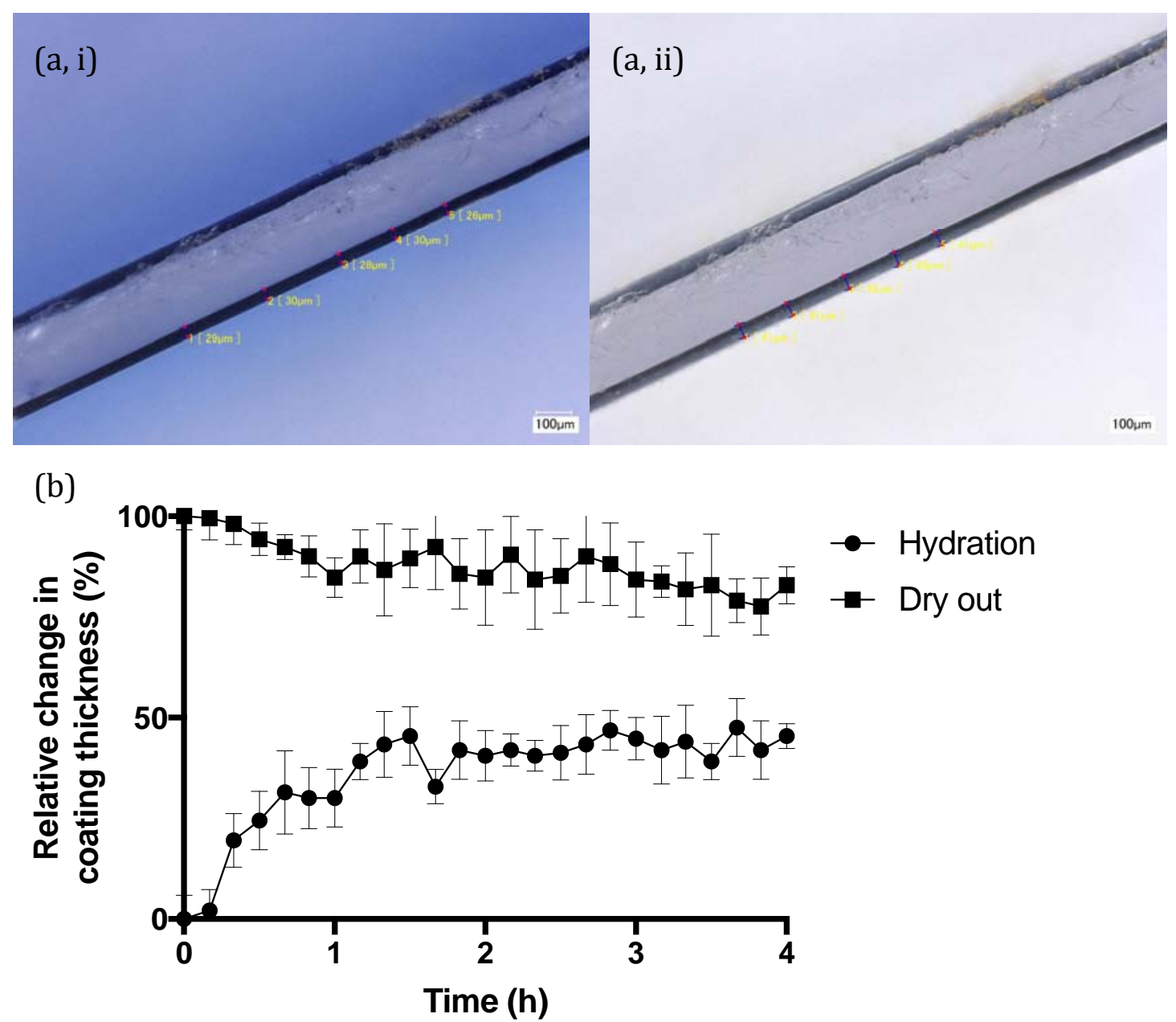

Figure 4. (a) Digital microscopy images of hydrogel-coated PVC (i) $0 \mathrm{~h}$ and (ii) $4 \mathrm{~h}$ post-hydration at 200x magnification. The coating was stained with TBO dye. (b) Relative change in coating thickness (\%) during hydration in, and following removal from, an aqueous solution of TBO. Values displayed are the mean of five replicate measurements and error bars represent standard deviations of the mean values.

The stained hydrogel coating can be seen in Figure 4 (a) as a uniform and distinct layer on the PVC surface. The significant increase in coating thickness upon hydration, as shown in Figure 4 (b), was attributed to the rapid uptake of water and resultant swelling of the hydrogel layer. A rapid and significant increase in coating thickness was observed after a 20 min period of hydration and the values appeared to plateau after 90 min when the thickness of the coating had increased by $45.5 \%$. An increase in surface 
lubricity has previously been reported with increased thickness of hydrophilic-coated layers as a result of the greater capacity for imbibement of water ${ }^{32}$. With regards to coating dry-out, no significant differences in coating thickness were observed until 200 min after removal from the wetting media when the coating had decreased in thickness by $15.7 \%$. The slower rates of coating dry-out demonstrate the ability of the hydrogel coating to retain the imbibed water, which is highly beneficial in clinical applications. Rapid loss of water from hydrophilic coatings has previously been found to increase resultant tissue damage as a result of the higher frictional forces between dried-out, 'sticky' coated surfaces and interfacing tissue ${ }^{35,36}$.

\subsection{Tribological assessment}

Tribological performance of the modified surfaces was assessed by measuring COF values of coated and uncoated PVC surfaces against a PDMS counterprobe under a normal applied load of $10 \mathrm{mN}$. COF values measured after varying periods of hydration in $\mathrm{dH}_{2} \mathrm{O}$ and $\mathrm{AU}(\mathrm{pH} 6$ and $\mathrm{pH}$ 9) are shown in Figure 5. 


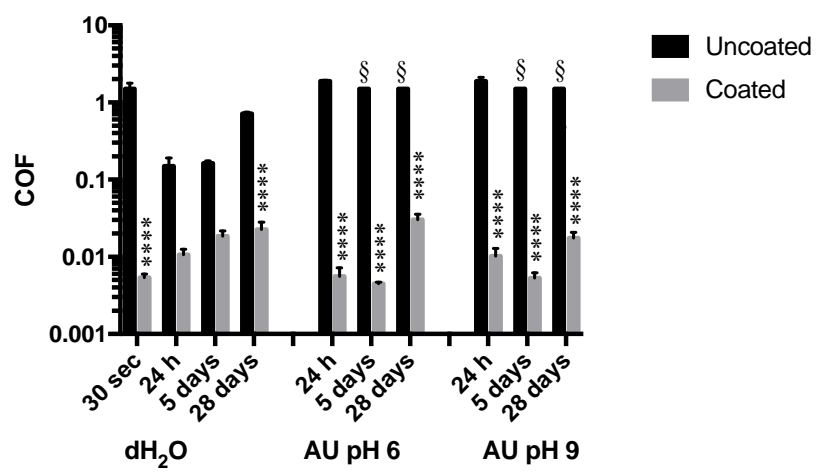

Figure 5. Cycle average COF values of coated and uncoated PVC surfaces following hydration in $\mathrm{dH}_{2} \mathrm{O}$ and AU. COF values have been averaged over the last fifty sliding cycles. Columns and error bars represent mean values \pm standard deviations $(n \geq 5)$. **** denotes significant difference in COF values relative to uncoated control $(p<0.0001)$. ${ }^{\S} \mathrm{COF}$ values were too high to be measured without damaging the counterprobe.

Under all testing conditions, coated PVC surfaces demonstrated significantly lower COF values than their uncoated counterparts, with mean COF values as low as 0.0045 against the PDMS probe following a five-day hydration period in $\mathrm{AU} \mathrm{pH}$ 6, thereby revealing the lubricious properties of the applied hydrogel coatings. The low frictional forces characteristic of hydrophilic surfaces are commonly associated with the presence of surface-localised lubricating layers of water and the corresponding increase in smoothness and lubricity of the surface ${ }^{30}$. In this case, the significant reductions in COF values relative to uncoated controls were attributed to the presence of the highly solvated hydrogel network resulting from the absorption of water molecules by the hydroxyl and carboxyl groups of the HEMA and PVP moieties ${ }^{13}$. In agreement with previous reports where friction was reported to be dependent on the degree of polymer solvation, this hydrated network was found to modify interfacial contact mechanics leading to lower contact pressures during sliding of the probe over the coated surface, with significant reductions in frictional forces ${ }^{13,37,38}$. 
COF values of the coated surfaces were, in addition, demonstrated to be independent of media $\mathrm{pH}$ after up to five days hydration in $\mathrm{AU}$ of $\mathrm{pH} 6$ and $\mathrm{pH} 9$. In contrast, rapid swelling of polyacrylic acid (PAA) hydrogels as $\mathrm{pH}$ of the wetting media was increased from $\mathrm{pH} 3$ (below the $\mathrm{pK}_{\mathrm{a}}$ of $\mathrm{PAA}$ ) to $\mathrm{pH} 10$ (above the $\mathrm{pK}_{\mathrm{a}}$ of PAA) resulted in $\mathrm{pH}$ responsive frictional properties of the artificial cartilage materials, namely high friction and superlubrication in acid conditions and alkaline media respectively ${ }^{39}$. While the effect of $\mathrm{pH}$ on tribological performance of hydrophilic catheter coatings has not previously been explored, the $\mathrm{pH}$-independent frictional behavior of the coatings developed herein from the nonionic monomer, HEMA, is of significant importance in consideration of their potential clinical application within the urinary tract, which maintains a normal physiological $\mathrm{pH}$ range between $\mathrm{pH} 4.8$ to $\mathrm{pH} 8$, with elevations up to $\mathrm{pH} 9.1$ reported during infection ${ }^{18,19}$.

In order to assess coating stability, tribological tests were performed with samples which had been incubating in $\mathrm{dH}_{2} \mathrm{O}$ or $\mathrm{AU}$ at $37^{\circ} \mathrm{C}$ for extended periods of up to 28 days, representing the duration that indwelling urinary catheters may be in situ within the bladder between scheduled device changes ${ }^{35}$. Importantly, as shown in Figure 5, the frictional response of coated surfaces was again more than 85 -fold lower than for uncoated PVC controls after a four-week incubation period. In the case of immersion in $\mathrm{dH}_{2} \mathrm{O}$ (Figure 5), an increased immersion time resulted in an increased COF; although significantly lower than the uncoated surfaces. This may be a result of dissolution of coating components upon prolonged incubation, with an accompanying change in coating integrity, osmotic pressure and resultant lubricity ${ }^{40}$. A similar observation was demonstrated for the coated surfaces immersed in AU (Figure 5), although the trends were not consistent with immersion time or $\mathrm{pH}$. 
Furthermore, no significant differences in frictional behavior of the coated surfaces were observed following hydration in $\mathrm{AU}$ or $\mathrm{dH}_{2} \mathrm{O}$, despite the osmotic differences between these two solutions. This is in contrast to alternative hydrogel systems of polyvinyl alcohol/polyvinylpyrrolidone (PVA/PVP), where significantly lower COF values were observed after swelling in polyethylene glycol (PEG)-based osmotic solution for 28 days relative to values obtained for their counterparts swollen in a nonosmotic PBS solution. These differences were attributed to deswelling of the PVA/PVP hydrogel in the former ionic environment and the corresponding decreased contact area between the two counterfaces during sliding ${ }^{40}$.

Durability of the coated surfaces following hydration in $\mathrm{dH}_{2} \mathrm{O}$ and $\mathrm{AU}$ for periods from $30 \mathrm{sec}$ to 28 days was assessed using the same tribological parameters outlined above. The COF values of surfaces following incubation in $\mathrm{dH}_{2} \mathrm{O}$ and $\mathrm{AU}$ have been plotted against cycle number in Figure 6 (a) and (b) respectively.

(a)

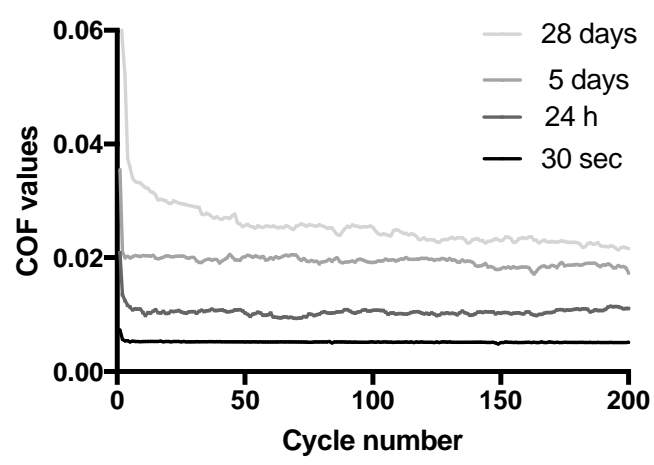

(b)

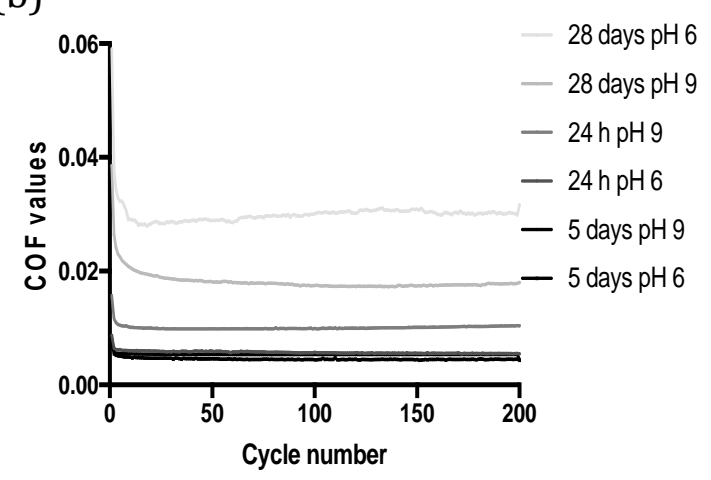

Figure 6. Mean COF values over 200 repeated sliding cycles on coated sample surfaces following hydration in (a) $\mathrm{dH}_{2} \mathrm{O}$ and (b) $\mathrm{AU}$. Error bars have been omitted for clarity however SD values were on average 7 -fold lower than their associated mean values. 
Coating delamination would be expected to cause an increase in frictional forces, with COF values ultimately approximating those obtained for uncoated surfaces $5,39,41$. In contrast, as shown in Figure 6, the COF values remained relatively stable for the duration of all tests, highlighting the impressive wear performance of the coated surfaces ${ }^{42}$. With increasing incubation time, an increase in the COF was seen for surfaces 'aged' in $\mathrm{dH}_{2} \mathrm{O}$ (Figure 6 (a)). A similar observation was also seen for surfaces 'aged' in AU, albeit to a higher extent compared to sample surfaces hydrated in $\mathrm{dH}_{2} \mathrm{O}$. In addition to time, the $\mathrm{pH}$ of the $\mathrm{AU}$ was also seen to affect the $\mathrm{COF}$ after extended periods of immersion time. These differences with time and hydration media may be related to degradation of films and exposure to charged species within the different hydration media, and could affect the mechanical and swelling properties of the coatings, subsequently affecting the tribological properties. Further work will be conducted to elucidate the links between coating degradation and tribological properties.

\subsection{Microbiological assessment}

Chlorhexidine, as a model antiseptic, was incorporated within the coating formulation to impart antibacterial properties and reduce the risk of device-associated infections ${ }^{43}$. Neutralizer toxicity testing revealed that the prepared neutralizer was not toxic to $P$. mirabilis or S. aureus, with $\leq 1 \log _{10}$ reductions in the test suspensions relative to the controls as shown in Table 2. Importantly, the neutralizer was also shown to effectively quench the activity of chlorhexidine, with $\leq 1 \log _{10}$ reductions in bacterial densities observed in the neutralized suspensions of chlorhexidine. 
Table 2: Viable Counts from Neutralizer Toxicity and Efficacy Testing

\begin{tabular}{lll}
\hline Test solution & $\boldsymbol{P}$. mirabilis $\left(\log _{\mathbf{1 0}} \mathbf{c f u} \mathbf{~ m L}^{-\mathbf{1}}\right)$ & S. aureus $\left(\log _{\mathbf{1 0}} \mathbf{c f u} \mathbf{~ m L}^{-\mathbf{1}}\right)$ \\
\hline Inoculum density at $\mathrm{t}=$ & $7.21 \pm 0.065$ & $7.51 \pm 0.020$ \\
$0 \mathrm{~h}$ & & \\
Toxicity test & $7.40 \pm 0.115$ & $7.36 \pm 0.125$ \\
Toxicity control & $7.26 \pm 0.038$ & $7.32 \pm 0.046$ \\
Efficacy test & $7.31 \pm 0.137$ & $6.89 \pm 0.058$ \\
Efficacy control & $<1.7$ & $<1.7$ \\
\hline
\end{tabular}

Device-associated infections and associated biofilm formation result from the initial adhesion of bacteria to implant surfaces ${ }^{44,45}$. To establish the capacity of the CLHcoated surfaces to prevent catheter-associated urinary tract infections, we herein evaluated the in vitro resistance of hydrogel-coated PVC and CLH-coated PVC to adherence of $P$. mirabilis and $S$. aureus relative to uncoated PVC in AU media. Samples of each material were challenged with inoculi of $P$. mirabilis and S. aureus (1 $\mathrm{x} 10^{6} \mathrm{cfu} \mathrm{mL} \mathrm{m}^{-1}$ ) over incubation periods of $4 \mathrm{~h}$ and $24 \mathrm{~h}$. Bacterial adherence to surfaces of the coated samples relative to uncoated PVC controls is displayed in Figure 7. 

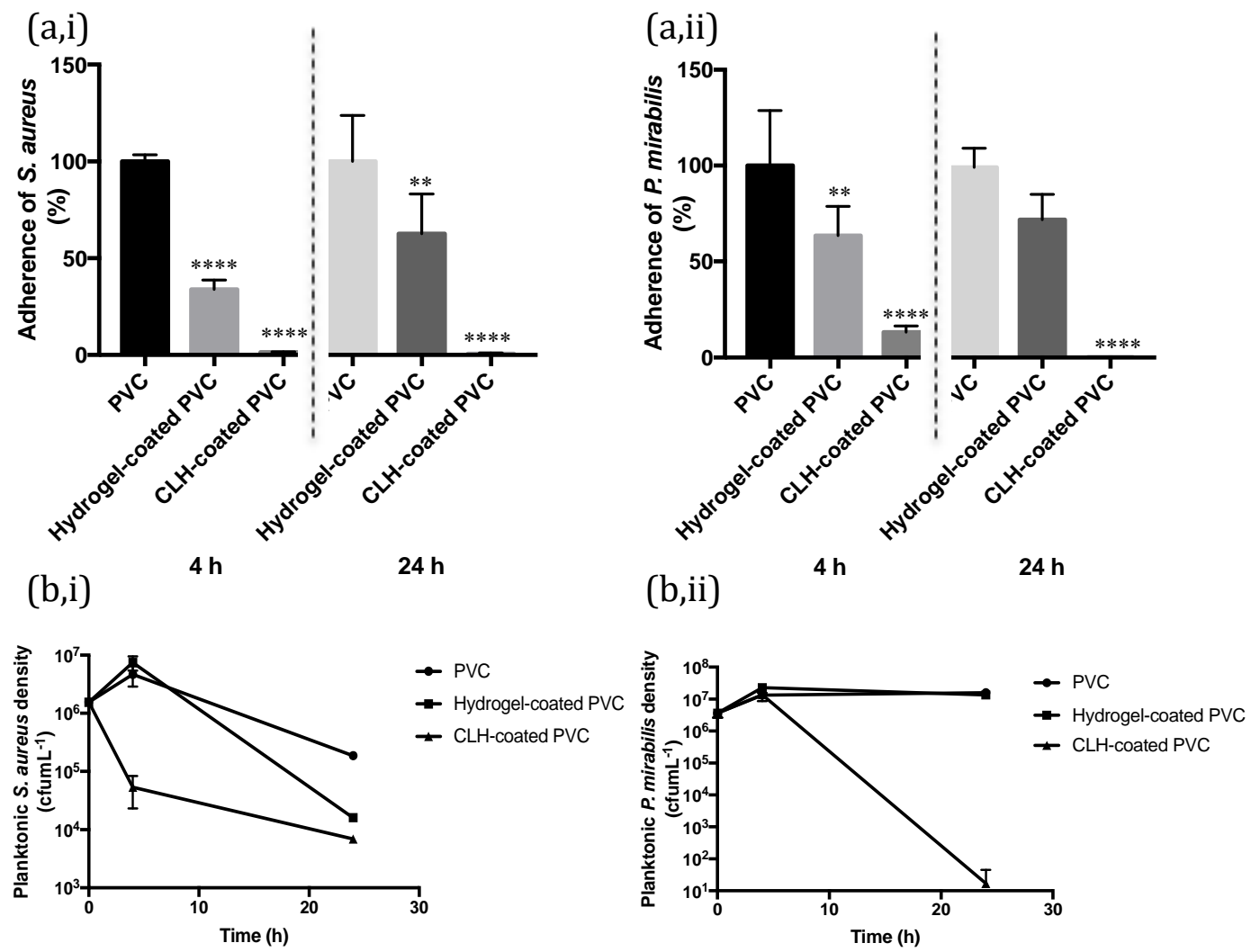

Figure 7. (a) Adherence (\%) of (i) S. aureus and (ii) P. mirabilis to the hydrogel- and CLH-coated PVC samples relative to uncoated PVC controls after $4 \mathrm{~h}$ and $24 \mathrm{~h}$ incubation at $37^{\circ} \mathrm{C}$. Columns and error bars represent mean values \pm standard deviations $(n \geq 5)$. *Denotes significant reduction in bacterial adherence relative to PVC control $(* * p<0.01, * * * * p<0.0001)$. (b) Viable counts of planktonic bacterial suspensions of (i) S. aureus and (ii) P. mirabilis after $4 \mathrm{~h}$ and $24 \mathrm{~h}$ incubation at $37^{\circ} \mathrm{C}$ in the presence of PVC, hydrogel-coated PVC and CLH-coated PVC. Error bars represent standard deviations of the mean values.

As shown in Figure 7 (a), significant reductions in bacterial colonization of up to $66 \%$ were observed on hydrogel-coated PVC relative to their uncoated counterparts. Reduced adherence of a range of common nosocomial pathogens, including S. aureus, Pseudomonas aeruginosa and Escherichia coli, to hydrophilic-coated surfaces relative to uncoated catheter substrates has previously been reported ${ }^{30,46,47}$. This lower degree of bacterial colonization is a result of the hydration layer formed from interactions of the hydrogel chains with water, which effectively acts as a hydrophilic barrier to 
bacterial adhesion ${ }^{34}$. Moreover, Figure 7 (a) demonstrates that incorporation of chlorhexidine provided an effective mechanism of increasing resistance of the coated surfaces to bacterial adherence, with significant logarithmic reductions in adherence of S. aureus and P. mirabilis relative to PVC controls approximating 2.42 and 2.72 , respectively, after $24 \mathrm{~h}$ incubation. This resistance was attributed to the surfacelocalised release of chlorhexidine, a cationic bisbiguanide antiseptic, with reported bactericidal activity against both Gram-positive and Gram-negative bacteria ${ }^{43}$. Chlorhexidine functions by disruption of bacterial membranes. Insertion of this agent between phospholipid headgroups, with associated displacement of membranelocalised divalent cations, $\mathrm{Mg}^{2+}$ and $\mathrm{Ca}^{2+}$, leads to loss of membrane fluidity and osmoregulation, and at higher concentrations loss of structural integrity and cellular contents $^{48}$.

In addition to their observed resistance to bacterial adherence, the CLH-coatings formulated herein demonstrated significant antimicrobial activity against the planktonic bacterial cultures, as shown in Figure 7 (b). After $4 \mathrm{~h}$ incubation with CLHcoated PVC, logarithmic reductions of up to 2.0 in the planktonic S. aureus suspension were achieved relative to the bacterial population in contact with the uncoated PVC, and after $24 \mathrm{~h}$ the logarithmic reductions in planktonic P. mirabilis approximated 6.0 in the presence of CLH-coated PVC. Chlorhexidine solutions and dressings are routinely used to cleanse central venous catheter exit sites towards the prevention of catheter-associated bloodstream infections and, while similar solutions have been used for periurethral cleansing before indwelling catheterization, there are to-date no marketed catheters containing this agent localised at the surface ${ }^{49-51}$. The facile manipulation, drug incorporation and drug-releasing capabilities of the lubricious 
surfaces engineered herein offer exciting potential for increasing resistance of biomaterial surfaces to colonizing bacteria and ultimately preventing associated infections.

\section{Conclusions}

The multifunctional biomaterial surfaces engineered herein displayed significant tribological performance, with COF values more than 300-fold lower than uncoated PVC. This behavior was, furthermore, independent of $\mathrm{pH}$ and, importantly, maintained after prolonged incubation and repeated applications of frictional force. In addition, microbiological testing confirmed the promising capacity of the CLH-coated surfaces to resist colonization of common clinical pathogens. These findings thereby highlight the promising potential of this robust and widely applicable surface modification approach to reduce device-related complications of tissue trauma, pain and infection.

\section{Acknowledgements}

This work was supported by the EPSRC-NIHR HTC Partnership IMPRESS Network (EP/N027345/1) and the Department for the Economy (Northern Ireland).

\section{Disclosures}

The authors declare no competing financial interests.

\section{Data availability}

Supporting data are openly available at https://doi.org/10.17034/d5148116-3dcf4998-b75d-0ef99dd650f2. 


\section{References}

1. McCoy, C. P.; Irwin, N. J.; Hardy, J. G.; Kennedy, S. J.; Donnelly, L.; Cowley, J. F.; Andrews, G. P.; Pentlavalli, S., Systematic optimization of poly(vinyl chloride) surface modification with an aromatic thiol. European Polymer Journal 2017, 97, 40-48.

2. Prokopovich, P.; Perni, S., Prediction of the frictional behavior of mammalian tissues against biomaterials. Acta Biomaterialia 2010, 6 (10), 4052-4059.

3. Jin, Z.; Zheng, J.; Li, W.; Zhou, Z., Tribology of medical devices. Biosurface and Biotribology 2016, 2 (4), 173-192.

4. $\quad$ Clark, J. F.; Mealing, S. J.; Scott, D. A.; Vogel, L. C.; Krassioukov, A.; Spinelli, M.; Bagi, P.; Wyndaele, J. J., A cost-effectiveness analysis of long-term intermittent catheterisation with hydrophilic and uncoated catheters. Spinal Cord 2016, 54 (1), 73-77.

5. Ho, S. P.; Nakabayashi, N.; Iwasaki, Y.; Boland, T.; LaBerge, M., Frictional properties of poly(MPC-co-BMA) phospholipid polymer for catheter applications. Biomaterials 2003, 24 (28), 5121-5129.

6. Wyndaele, J. J., Complications of intermittent catheterization: their prevention and treatment. Spinal Cord 2002, 40 (10), 536-541.

7. Vapnek, J. M.; Maynard, F. M.; Kim, J., A prospective randomized trial of the LoFric hydrophilic coated catheter versus conventional plastic catheter for clean intermittent catheterization. Journal of Urology 2003, 169 (3), 994-998.

8. Newman, D. K.; Willson, M. M., Review of intermittent catheterization and current best practices. Urologic Nursing 2011, 31 (1), 12-29.

9. Nickel, J. C.; Olson, M. E.; Costerton, J. W., In vivo coefficient of kinetic friction - study of urinary catheter biocompatibility. Urology 1987, 29 (5), 501-503.

10. Aygin, D.; Usta, E., The effect of lubricants used in indwelling bladder catheterization through urethra on procedure-related pain: a literature review. International Journal of Clinical and Experimental Medicine 2017, 10 (2), 19952005.

11. Stensballe, J.; Looms, D.; Nielsen, P. N.; Tvede, V., Hydrophilic-coated catheters for intermittent catheterisation reduce urethral microtrauma: A prospective, randomised, participant-blinded, crossover study of three different types of catheters. European Urology 2005, 48 (6), 978-983.

12. Waller, L.; Jonsson, O.; Norlen, L.; Sullivan, L., Clean intermittent catheterization in spinal-cord injury patients - long-term follow-up of a hydrophilic low-friction technique. Journal of Urology 1995, 153 (2), 345-348.

13. Niemczyk, A.; El Fray, M.; Franklin, S. E., Friction behaviour of hydrophilic lubricious coatings for medical device applications. Tribology International 2015, 89, 54-61.

14. Chai, T.; Chung, A. K.; Belville, W. D.; Faerber, G. J., Compliance and complications of clean intermittent catheterization in the spinal-cord injured patient. Paraplegia 1995, 33 (3), 161-163.

15. De Ridder, D.; Everaert, K.; Fernandez, L. G.; Valero, J. V. F.; Duran, A. B.; Abrisqueta, M. L. J.; Ventura, M. G.; Sotillo, A. R., Intermittent catheterisation with hydrophilic-coated catheters (SpeediCath) reduces the risk of clinical urinary tract infection in spinal cord injured patients: A prospective randomised parallel comparative trial. European Urology 2005, 48 (6), 991-995.

16. Armbruster, C. E.; Forsyth-DeOrnellas, V.; Johnson, A. O.; Smith, S. N.; Zhao, L.; Wu, W.; Mobley, H. L. T., Genome-wide transposon mutagenesis of 
Proteus mirabilis: Essential genes, fitness factors for catheter-associated urinary tract infection, and the impact of polymicrobial infection on fitness requirements. Plos Pathogens 2017, 13 (6), e1006434-e1006434.

17. Armbruster, C. E.; Prenovost, K.; Mobley, H. L. T.; Mody, L., How often do clinically diagnosed catheter-associated urinary tract infections in nursing homes meet standardized criteria? Journal of the American Geriatrics Society 2017, 65 (2), 395401 .

18. Stickler, D. J.; Morgan, S. D., Modulation of crystalline Proteus mirabilis biofilm development on urinary catheters. Journal of Medical Microbiology 2006, 55 (5), 489-494.

19. Irwin, N. J.; McCoy, C. P.; Carson, L., Effect of $\mathrm{pH}$ on the in vitro susceptibility of planktonic and biofilm-grown Proteus mirabilis to the quinolone antimicrobials. Journal of Applied Microbiology 2013, 115 (2), 382-389.

20. Milo, S.; Hathaway, H.; Nzakizwanayo, J.; Alves, D. R.; Esteban, P. P.; Jones, B. V.; Jenkins, A. T. A., Prevention of encrustation and blockage of urinary catheters by Proteus mirabilis via $\mathrm{pH}$-triggered release of bacteriophage. Journal of Materials Chemistry B 2017, 5 (27), 5403-5411.

21. Liak, T. L.; Po, A. L. W.; Irwin, W. J., The effects of drug-therapy on urinary $\mathrm{pH}$ - excipient effects and bioactivation of methenamine. International Journal of Pharmaceutics 1987, 36 (2-3), 233-242.

22. Remer, T.; Manz, F., Potential renal acid load of foods and its influence on urine pH. Journal of the American Dietetic Association 1995, 95 (7), 791-797.

23. Cox, A. J.; Hukins, D. W. L.; Davies, K. E.; Irlam, J. C.; Sutton, T. M., An automated technique for in vitro assessment of the susceptibility of urinary catheter materials to encrustation. Engineering in Medicine 1987, 16 (1), 37.

24. Lanigan, J.; Fatima, S.; Charpentier, T.; Neville, A.; Dowson, D.; Bryant, M., Lubricious ionic polymer brush functionalised silicone elastomer surfaces.

Biotribology 2018, 16, 1-9.

25. Knapp, L.; Rushton, L.; Stapleton, H.; Sass, A.; Stewart, S.; Amezquita, A.; McClure, P.; Mahenthiralingam, E.; Maillard, J. Y., The effect of cationic microbicide exposure against Burkholderia cepacia complex (Bcc); the use of Burkholderia lata strain 383 as a model bacterium. Journal of Applied Microbiology 2013, 115 (5), 1117-1126.

26. Jones, D. S.; McGovern, J. G.; Woolfson, A. D.; Gorman, S. P., Role of physiological conditions in the oropharynx on the adherence of respiratory bacterial isolates to endotracheal tube poly(vinyl chloride). Biomaterials 1997, 18 (6), 503-510. 27. Miles, A. A.; Misra, S. S.; Irwin, J. O., The estimation of the bactericidal power of the blood. The Journal of Hygiene 1938, 38 (6), 732-749.

28. McCoy, C. P.; Irwin, N. J.; Brady, C.; Jones, D. S.; Carson, L.; Andrews, G. P.; Gorman, S. P., An infection-responsive approach to reduce bacterial adhesion in urinary biomaterials. Molecular Pharmaceutics 2016, 13 (8), 2817-2822.

29. Coates, J., Interpretation of infrared spectra, a practical approach. In Encyclopedia of Analytical Chemistry, 1 ed.; Meyers, R. A., Ed. John Wiley and Sons Ltd.: Chichester, 2000; pp 10815-10837.

30. Yang, S.-H.; Lee, Y.-S. J.; Lin, F.-H.; Yang, J.-M.; Chen, K.-S., Chitosan/poly(vinyl alcohol) blending hydrogel coating improves the surface characteristics of segmented polyurethane urethral catheters. Journal of Biomedical Materials Research Part B-Applied Biomaterials 2007, 83B (2), 304-313.

31. Okano, T.; Nishiyama, S.; Shinohara, I.; Akaike, T.; Sakurai, Y.; Kataoka, K.; Tsuruta, T., Effect of hydrophilic and hydrophobic microdomains on mode of 
interaction between block polymer and blood-platelets. Journal of Biomedical Materials Research 1981, 15 (3), 393-402.

32. Hanssen, H. H. L.; Wetzels, G. M. R.; Benzina, A.; van der Veen, F. H.; Lindhout, T.; Koole, L. H., Metallic wires with an adherent lubricious and bloodcompatible polymeric coating and their use in the manufacture of novel slipperywhen-wet guidewires: Possible applications related to controlled local drug delivery. Journal of Biomedical Materials Research 1999, 48 (6), 820-828.

33. Yuan, Y.; Hays, M. P.; Hardwidge, P. R.; Kim, J., Surface characteristics influencing bacterial adhesion to polymeric substrates. RSC Advances 2017, 7 (23), 14254-14261.

34. Ngo, B. K. D.; Grunlan, M. A., Protein resistant polymeric biomaterials. ACS Macro Letters 2017, 6 (9), 992-1000.

35. Irwin, N. J.; McCoy, C. P.; McCullough, A. R.; Corbett, D. J., Use of in vitro and haptic assessments in the characterisation of surface lubricity. Proceedings of the Institution of Mechanical Engineers Part H-Journal of Engineering in Medicine 2019, 233 (1), 84-90.

36. Fader, M.; Moore, K. N.; Cottenden, A. M.; Pettersson, L.; Brooks, R.; Malone-Lee, J., Coated catheters for intermittent catheterization: smooth or sticky? BJU international 2001, 88 (4), 373-377.

37. Rudy, A.; Kuliasha, C.; Uruena, J.; Rex, J.; Schulze, K. D.; Stewart, D.; Angelini, T.; Sawyer, W. G.; Perry, S. S., Lubricous hydrogel surface coatings on polydimethylsiloxane (PDMS). Tribology Letters 2017, 65 (1), 3-3.

38. Pitenis, A. A.; Uruena, J. M.; Schulze, K. D.; Nixon, R. M.; Dunn, A. C.; Krick, B. A.; Sawyer, W. G.; Angelini, T. E., Polymer fluctuation lubrication in hydrogel gemini interfaces. Soft Matter 2014, 10 (44), 8955-8962.

39. Ma, S. H.; Scaraggi, M.; Wang, D. A.; Wang, X. L.; Liang, Y. M.; Liu, W. M.; Dini, D.; Zhou, F., Nanoporous substrate-infiltrated hydrogels: a bioinspired regenerable surface for high load bearing and tunable friction. Advanced Functional Materials 2015, 25 (47), 7366-7374.

40. Shi, Y.; Xiong, D. S.; Liu, Y. T.; Wang, N.; Zhao, X. D., Swelling, mechanical and friction properties of PVA/PVP hydrogels after swelling in osmotic pressure solution. Materials Science \& Engineering C-Materials for Biological Applications 2016, 65, 172-180.

41. Anil, M.; Ahmed, S. F.; Yi, J. W.; Moon, M. W.; Lee, K. R.; Kim, Y. C.; Seok, H. K.; Han, S. H., Tribological performance of hydrophilic diamond-like carbon coatings on Ti-6Al-4V in biological environment. Diamond and Related Materials 2010, 19 (4), 300-304.

42. Dunn, A. C.; Sawyer, W. G.; Angelini, T. E., Gemini interfaces in aqueous lubrication with hydrogels. Tribology Letters 2014, 54 (1), 59-66.

43. Cassir, N.; Thomas, G.; Hraiech, S.; Brunet, J.; Fournier, P. E.; La Scola, B.; Papazian, L., Chlorhexidine daily bathing: Impact on health care-associated infections caused by gram-negative bacteria. American Journal of Infection Control 2015, 43 (6), 640-643.

44. Irwin, N. J.; McCoy, C. P.; Jones, D. S.; Gorman, S. P., Infection-responsive drug delivery from urinary biomaterials controlled by a novel kinetic and thermodynamic approach. Pharmaceutical Research 2013, 30 (3), 857-865.

45. Xu, X.; Li, Y. L.; Wang, L. X.; Li, Y.; Pan, J. J.; Fu, X. M.; Luo, Z. Y.; Sui, Y.; Zhang, S. Q.; Wang, L.; Ni, Y. F.; Zhang, L.; Wei, S. C., Triple-functional polyetheretherketone surface with enhanced bacteriostasis and anti-inflammatory and osseointegrative properties for implant application. Biomaterials 2019, 212, 98-114. 
46. Kristinsson, K. G., Adherence of Staphylococci to intravascular catheters. Journal of Medical Microbiology 1989, 28 (4), 249-257.

47. Bridgett, M. J.; Davies, M. C.; Denyer, S. P.; Eldridge, P. R., In vitro assessment of bacterial adhesion to hydromer(r)-coated cerebrospinal-fluid shunts. Biomaterials 1993, 14 (3), 184-188.

48. Wand, M. E.; Bock, L. J.; Bonney, L. C.; Sutton, J. M., Mechanisms of increased resistance to chlorhexidine and cross-resistance to colistin following exposure of klebsiella pneumoniae clinical isolates to chlorhexidine. Antimicrobial Agents and Chemotherapy 2017, 61 (1), 1-12.

49. McCann, M.; Fitzpatrick, F.; Mellotte, G.; Clarke, M., Is 2\% chlorhexidine gluconate in $70 \%$ isopropyl alcohol more effective at preventing central venous catheter-related infections than routinely used chlorhexidine gluconate solutions: A pilot multicenter randomized trial (ISRCTN2657745)? American Journal of Infection Control 2016, 44 (8), 948-949.

50. Karpanen, T. J.; Casey, A. L.; Whitehouse, T.; Nightingale, P.; Das, I.; Elliott, T. S. J., Clinical evaluation of a chlorhexidine intravascular catheter gel dressing on short-term central venous catheters. American Journal of Infection Control 2016, 44 (1), 54-60.

51. Duzkaya, D. S.; Uysal, G.; Bozkurt, G.; Yakut, T.; Citak, A., Povidoneiodine, $0.05 \%$ chlorhexidine gluconate, or water for periurethral cleaning before indwelling urinary catheterization in a pediatric intensive care: a randomized controlled trial. Journal of Wound Ostomy and Continence Nursing 2017, 44 (1), 8488 .

Table of contents graphic

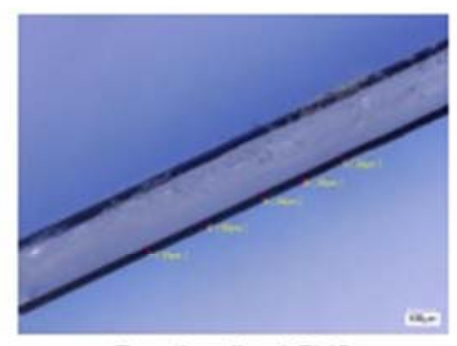

Functionalised PVC
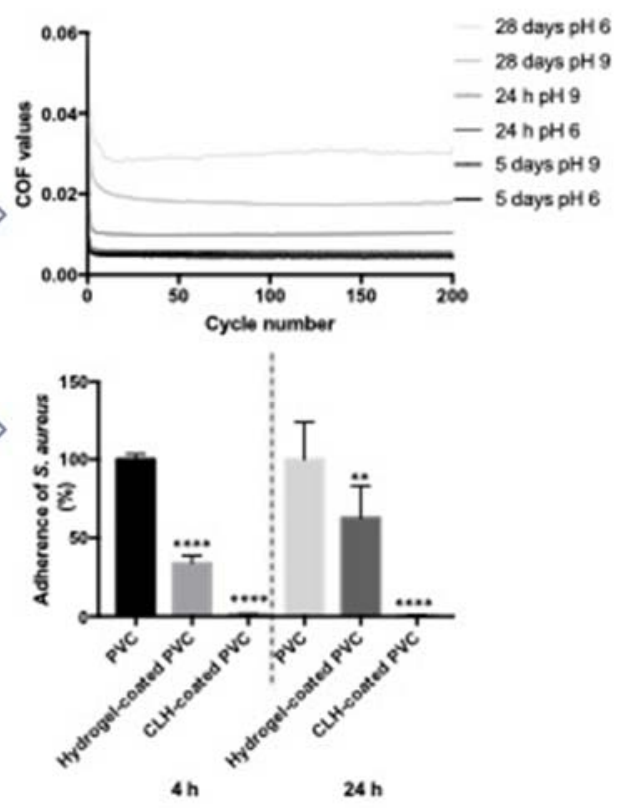